\title{
Pulse oximetry: the outstanding achievements of Dr. Takuo Aoyagi
}

\author{
Michiaki Yamakage $^{1}$ (D)
}

Received: 6 June 2021 / Accepted: 30 June 2021 / Published online: 8 July 2021

(c) Japanese Society of Anesthesiologists 2021

Dr. Takuo Aoyagi, the father of the pulse oximeter, passed away last year. To commemorate the first anniversary of his death, people closely associated with Dr. Aoyagi and with pulse oximetry have submitted contributions to LiSA, a commercial Japanese journal, with Prof. Katsuyuki Miyasaka (Professor Emeritus, St. Luke's International University) playing a central role. For those of us not familiar with the development and history of pulse oximetry, these articles were of great interest and provided an opportunity to learn of its contributions to anesthesia management and patient safety in the intensive care unit and in emergency settings. This project is of course a result of the efforts of the contributors, but I don't think it would have come to fruition without the hard work of Prof. Miyasaka, who oversaw the submissions and the Japanese translation of manuscripts from overseas contributors.

When members of the JSA International Exchange Committee learned of this project, they were of the opinion that it would be a shame for these valuable submissions to appear in Japanese only, and that they should also be published in English to be read by medical professionals around the world. Prof. Miyasaka consulted me in my capacity as the editor-in-chief of the Journal of Anesthesia (JA) at that time. When I mentioned this to Prof. Evan Kharasch (Duke University), who was the editor-in-chief of Anesthesiology, he replied that there were plans to publish a special 35th anniversary issue of the APSF Newsletter, and that of course there would be an opportunity to highlight Dr. Aoyagi's contributions to pulse oximetry. He said that the APSF Newsletter would publish its 35th anniversary issue at almost the same time of publication as the special articles gathered by Prof. Miyasaka. Therefore, the Japanese translations of "a 35 Year Commitment to Patient Safety" were carried in LiSA but were not reprinted in the $J A$. We discussed various

Michiaki Yamakage

yamakage@sapmed.ac.jp

1 Department of Anesthesiology, Sapporo Medical University School of Medicine, South-1, West-16, Chuo-ku, Sapporo, Hokkaido 060-8543, Japan ways to publish English versions of these articles, in the end choosing that Prof. Miyasaka would be in charge of the English translations of the manuscripts from the Japanese contributors, and that I would arrange them in a form suitable for publication in the $J A$. I was able to learn much about Prof. Miyasaka's thoughts on the field from this. He assembled the articles in a very short time, and they arrived at my office in late March 2021. When I first looked at the manuscripts, I was amazed at the great quality and volume, but was then at a loss as to how to go about condensing them to a form suited to the $J A$. I copied the folder to my computer desktop, but then can't recall how many times I clicked the folder open, closed it, and let out a sigh.

In April, $J A$ appointed a new editor-in-chief, and I decided to dedicate an allotted time to peer review/editing of these special articles. In doing so, I tried to (1) condense them a little without changing the meaning that the authors wanted to convey, and (2) select the figures and references that would stand up to peer review in an English-language journal so that there would be no problems for submission to an international journal. Now, after several months, we have obtained all authors' permission for publication, and after clarifying that similar articles have been published in the commercial Japanese language magazine LiSA, put the articles through peer review for $J A$. We are proud to have had the opportunity to share the great achievements of Dr. Aoyagi with the world through these special articles.

It would be a tremendous joy to Prof. Miyasaka and the various authors, as well as myself, if these special articles were to continue to be read with respect throughout the world to share the great things Dr. Aoyagi achieved in this field, which are worthy of the Nobel Prize.

I pray most sincerely that Dr. Aoyagi's soul rests in peace.

Publisher's Note Springer Nature remains neutral with regard to jurisdictional claims in published maps and institutional affiliations. 